\title{
Growth promoting properties of Mycobacterium and Bacillus on rice plants under induced drought
}

\author{
Joydip Karmakar ${ }^{1}$, Sayani Goswami ${ }^{1}$, Krishnendu Pramanik ${ }^{3}$, Tushar Kanti Maiti², Rup Kumar Kar ${ }^{3}$ \& \\ Narottam Dey ${ }^{1^{*}}$ \\ ${ }^{1}$ Rice Biotechnology laboratory, Department of Biotechnology, Visva-Bharati, Santiniketan 731 235, West Bengal, India \\ ${ }^{2}$ Department of Botany, The University of Burdwan, Burdwan 713 104, West Bengal, India \\ ${ }^{3}$ Department of Botany, Visva-Bharati, Santiniketan 731 235, West Bengal, India \\ *Email: narottam.dey@visva-bharati.ac.in
}

\section{ARTICLE HISTORY}

Received: 18 September 2020 Accepted: 26 November 2020

Published: 01 January 2021

\section{KEYWORDS}

Rice

Drought

PGPR

16S rDNA

Mycobacterium sp.

Bacillus sp.

\section{ABSTRACT}

Management of drought stress through application of plant growth promoting rhizobacteria (PGPR) is now considered as an effective strategy in the present scenario of altered environmental conditions of the world. The aims and objectives of the present investigation was isolation, characterization and identification of some potential microbial resources (PGPR) from drought-affected upland rice fields of South Bengal followed by experimentation on the effect of isolated PGPR on drought induced rice seedlings. Selected isolates were isolated from rice field rhizospheric soils and tested for their PGPR activity, through phosphate solubilization, nitrogen fixation, IAA production and ACC deaminase activity. Then, the selected isolates were identified through $16 \mathrm{~S}$ rDNA sequencing and phylogenetic analysis. Among the screened isolates two (isolate 1 and isolate 6) showing plant growth promoting traits, was applied on studied germplasm (IR64) to find out the influence of the applied organisms on rice growth and development under induced drought. Both organisms showed a positive influence (through increase in germination percentage, root growth, shoot growth, fresh weight and dry weight) on the studied rice growth and development under induced drought. Isolate 1 and 6 identified as species of Mycobacterium sp. and Bacillus sp. respectively through molecular taxonomy. Hence, these two isolates are expected to alleviate drought stress in the rice field for their nature of plant growth promotion under drought stress.

\section{Introduction}

Among the different abiotic factors, drought is one of the major constraints that adversely affect rice plant's growth and productivity worldwide and it is expected that drought will hamper rice production in more than $50 \%$ of the arable lands by 2050 (1). Also increase in population, decrease in arable lands due to urbanization and constant increasing global warming makes the situation more adverse (2).

Plants response to drought in several ways including reduction in cellular water potential, closure of stomata, decrease in the rate of photosynthesis, nitrate assimilation and generation of a number of antioxidative enzymes like Super oxide dismutase (SOD), Catalase (CAT), Peroxidase etc. (3).

A variety of strategies has been used to improve the drought tolerance of rice like conventional stress management, different breeding approaches, genetic engineering etc. $(4,5)$. Though the most successful strategy for management of drought tolerance is the use of drought tolerant potent rice genotypes and introgression of drought tolerance in higher yield background but the strategy is very complex and long time consuming (6). So researchers are looking for different and easy techniques to achieve their goal. Use of PGPR in relation to stress management is one of them. It is one of the recently employed strategy

(c) Karmakar et al (2021). This is an open-access article distributed under the terms of the Creative Commons Attribution License, which permits unrestricted use distribution and reproduction in any medium, provided the original author and source are credited (https://creativecommons.org/licenses/by/4.0/)

To cite this article: Karmakar J, Goswami S, Pramanik K, Maiti T K, Kar R K, Dey N. Growth promoting properties of Mycobacterium and Bacillus on rice plants under induced drought. Plant Science Today. 2021;8(1):49-57. https://doi.org/10.14719/pst.2021.8.1.965

Abbreviations: PGPR: Plant growth promoting rhizobacteria; BOD: Biological oxygen demand; IAA: Indole acetic acid; ACC: 1-aminocyclopropane-1-carboxylic acid; LB: Luria-Bertani; PKV: Pikovskaya's; PSI: Phosphate solubilization index; DM: Davis and Mingioli; DF: Dworkin and Foster; PBS: Phosphate buffer saline; ANOVA: Analysis of variance. 
which promote plant growth and development by virtue of production hormone and availability of micronutrients (7). Available reports suggest that the beneficial native rhizospheric bacteria that colonize in the plant roots resulted in the production of growth promoting hormones and some essential micronutrients which help the rice plants to survive and also help to avoid the period of adverse environment (7). As this approach is relatively new there is lack of resource of information related to PGPR in relation to rice drought stress management. Keeping this in mind a research attempt was taken to isolate selective PGPR from a drought prone upland rice field soil followed by application of the investigated microorganisms on a drought susceptible rice lines maintained under differentially induced drought stress.

\section{Materials and Methods}

\section{Collection, isolation and enrichment}

Soil samples were collected from selected rice fields of four drought-prone districts (Bankura, Birbhum, Purulia and West Midnapur) of South Bengal (Fig. 1) randomly to make the collection diverse.

Ten gram soil samples were taken from the rhizospheric regions (about 2 to $3 \mathrm{~cm}$ beneath of surface) and mixed with $90 \mathrm{ml}$ of distilled water followed by serial dilution $\left(10^{-7}\right) .100 \mu \mathrm{l}$ diluted

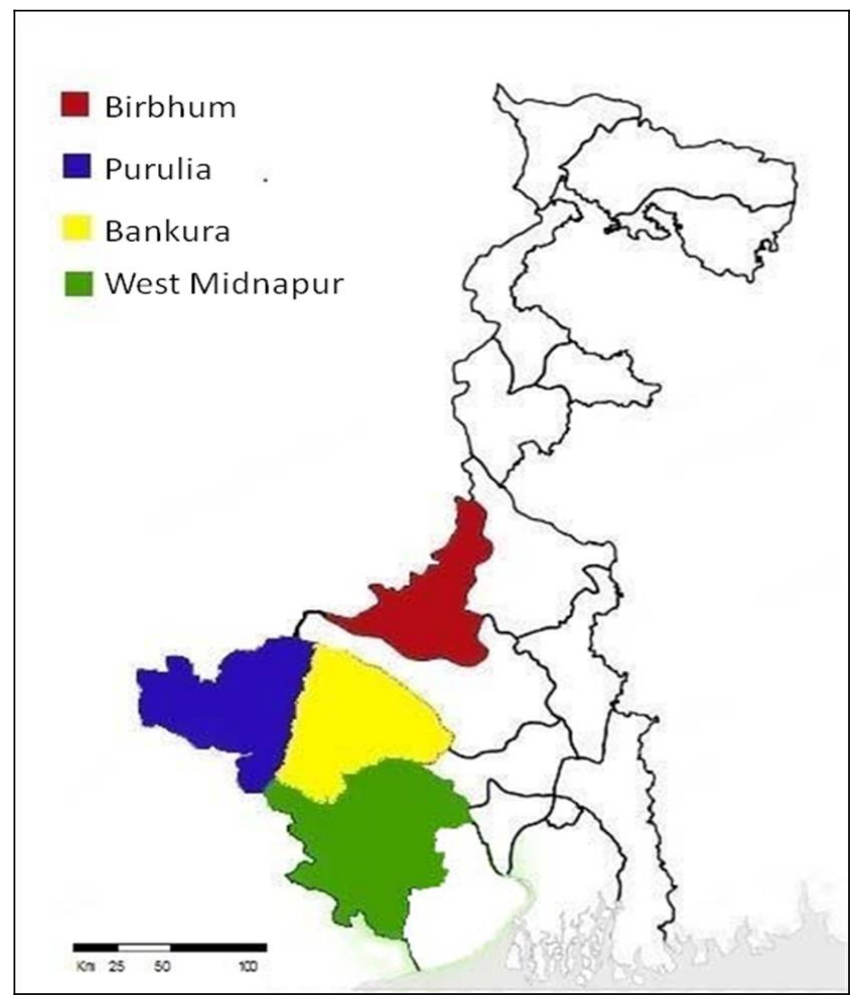

Fig.1. Four drought-prone district of West Bengal from where soil samples were colleted for the study.

suspension was spread on the LB (Luria-Bertani) agar plate and incubated in BOD incubator at $28 \pm 1^{\circ} \mathrm{C}$ for $72 \mathrm{hrs}$. After appearance of colonies, each isolate was purified though pure culture technique (8) and screened for PGPR activity.

\section{Characterization of selected isolates as PGPR}

For characterization of the selected isolates as PGPR, four important characteristics have been chosen for the study, such as, phosphate solubilisation, nitrogen fixation, IAA production and ACC deaminase production.

\section{Phosphate solubilization}

Phosphate solubilization property was tested through plating the microbial isolates on PKV agar medium (9) and incubated at $28 \pm 1^{\circ} \mathrm{C}$ for 5 days. Clear halo zone around microbial colonies were considered as the activity of phosphate solubilizing property of the tested organisms and colonies were further purified by re-streaking on the fresh PKV agar plates to confirm their phosphate solubilizing capability. The ability of the isolate to solubilize insoluble phosphate was expressed in the form of PSI following the standard protocol (10) and amount of soluble phosphate was quantified spectrophotometrically. The amount of soluble phosphate per ml culture was estimated using a standard curve prepared by dipotassium hydrogen phosphate.

\section{Nitrogen fixation}

Nitrogen-fixing ability of the selected isolates were tested in Burk's Nitrogen-free medium (11) and incubated for 7 days at $28 \pm 1^{\circ} \mathrm{C}$. The development of bacterial colonies in nitrogen-free medium was considered as nitrogen fixing ability of the isolates.

\section{IAA production}

In order to confirm the IAA production property, the isolates were grown in DM medium (12) supplemented with filtered sterilized L-tryptophan (1 $\mathrm{mg} / \mathrm{ml}$ ) for $72 \mathrm{hr}$ in a BOD incubator. Following incubation, cells were removed from the culture media by centrifugation (10000 rpm for $12 \mathrm{~min}$ ). IAA was estimated spectrophotometrically according to the standard method (13).

\section{Acc deaminase activity}

The enzymatic activity of ACC deaminase for the isolates was estimated following standard protocol (14). The isolates were inoculated in agar plates with carbon and nitrogen free DF minimal medium (15) supplemented with ACC where ACC act as sole carbon and/ or nitrogen source. The plates were incubated for 10 days at $28 \pm 1^{\circ} \mathrm{C}$ and observed regularly for colony formation. ACC deaminase activity of the studied organisms was confirmed through sub culturing. The newly formed colonies in carbon and nitrogen-free DF medium added with ACC were taken positive for ACC deaminase activity. Carbon and nitrogen free DF salt minimal medium without ACC was used as a control, in which no colony appeared. The amount of ACC deaminase activity was quantified following a modified method (16), which estimates the amount of a-ketobutyrate produced when the ACC deaminase cleaves ACC. The amount of a-ketobutyrate was quantified spectrophotometrically using a standard curve of a-ketobutyrate. One unit of ACC deaminase activity indicated the formation of 1 nmol of a-ketobutyrate per mg protein per hour. The protein content in the enzyme extract was estimated following the Bradford method (17). 


\section{Identification}

For identification of the selected isolates, phylogenetic analysis was done using 16S rDNA sequence. The genomic DNA was isolated and amplified with universal primers 8F [5'AGAGTTTGATCCTGGCTCAG3'] and 1492R [5'ACGGCTACCTTGTTACGACTT3'] (18) for amplification of 16S rDNA gene followed by sequencing. The derived sequences were searched for homology searching through BLAST in NCBI Gene bank. Neighbor-joining phylogenetic tree of the studied sequences was constructed (19) using the MEGA 6.0 (20). After phylogenetic analysis, the studied sequences were submitted to NCBI Gene bank and registered in NCBI gene bank as VBBAN1 (KF059963) and VBBAN2 (KF705063).

\section{Effect of the selected isolates on rice growth under induced drought stress}

The characterized isolates were grown in LB medium at $28 \pm 1^{\circ} \mathrm{C}$ followed by centrifugation ( $3000 \mathrm{rpm}$ for $5 \mathrm{mint}$ ) and the pellet was washed twice with PBS followed by re-suspension in $5 \mathrm{ml}$ of PBS (containing $1 \times 10^{8}$ cells $/ \mathrm{ml}$ ) to produce inoculum for studying the growth promoting effect of the studied microorganisms on the rice plant under induced drought.

IR64 (Accession Number: AC-41106), a high yielding drought susceptible rice line was selected for the study of possible growth promoting effect under induced drought. Seeds were surface sterilized and then dipped into $5 \mathrm{ml}$ of PBS suspension for $2.5 \mathrm{hrs}$ followed by sowing separately in a series of pots filled with sterile soils soaked with $-0.5 \mathrm{MPa},-1.0 \mathrm{MPa}$ and -1.5 MPa PEG6000 solutions [following Money, 1989 (21)] with one control set where seeds were placed only in distilled water. Two screening sets (for two isolates) were maintained in triplicate with each pot containing three healthy seedlings. All the pots were incubated at ideal growth condition $\left(28 \pm 1^{\circ} \mathrm{C}\right.$ temperature, 70-80 \% humidity, $14 \mathrm{hr}$ light, and $10 \mathrm{hr}$ dark cycle) for 20 days in a plant growth chamber (Daihan Labtech, India, LGC-5201). During the incubation period, pots were supplemented with the respective cultures $(1 \mathrm{ml}$ culture suspended in PBS containing $1 \times 10^{8}$ cells $/ \mathrm{ml}$ ) after every 5 days interval. After 20 days of incubation, germination percentage, shoot length, root length, fresh weight of shoot, fresh weight of root, dry weight of shoot and dry weight of root of the plants were measured to check the effect of the selected isolates on plant growth and promotion in control and under induced stress.

\section{Statistical analysis}

All the data were represented as mean \pm SE of three replicates. Results were subjected to one-way ANOVA for assessing the significance of all the screening. Duncan's test $(\mathrm{P} \leq 0.05)(22)$ was performed as post hoc on parameters subjected to ANOVA. All the statistical tests were performed using SPSS16.0 software.

\section{Results}

After initial screening, sixteen different isolates were isolated which showed profuse growth in the medium and screened for their PGPR activity.

\section{Characterization of selected isolates as PGPR}

\section{Phosphate solubilization}

Isolate 1 (I 1) and isolate 6 (I 6) have shown phosphate solubilizing activity (shown halo zone around the colonies in PKV agar medium after incubation). Isolate 1 showed higher PSI (2.333) than I 6 (1.333). The amount of phosphate solubilizing activity of isolate 1 and 6 was also quantified 1.266 and $0.98 \mathrm{mg} / \mathrm{ml}$ respectively (Fig. 2).

\section{Nitrogen fixation}

Among the selected isolates I 1 and I 6 also showed nitrogen fixing ability as shown by the ability to grow in Burk's nitrogen free media (Fig. 3).

\section{IAA production}

The isolates I1 and I6 showed IAA production in DM medium. Comparative IAA production ability of the two isolates is presented in Fig. 4 where I 1 showed $1287.5 \mathrm{mmole} / \mathrm{h} / \mathrm{mg}$ and I 6 showed $1212.5 \mathrm{mmole} / \mathrm{h} /$

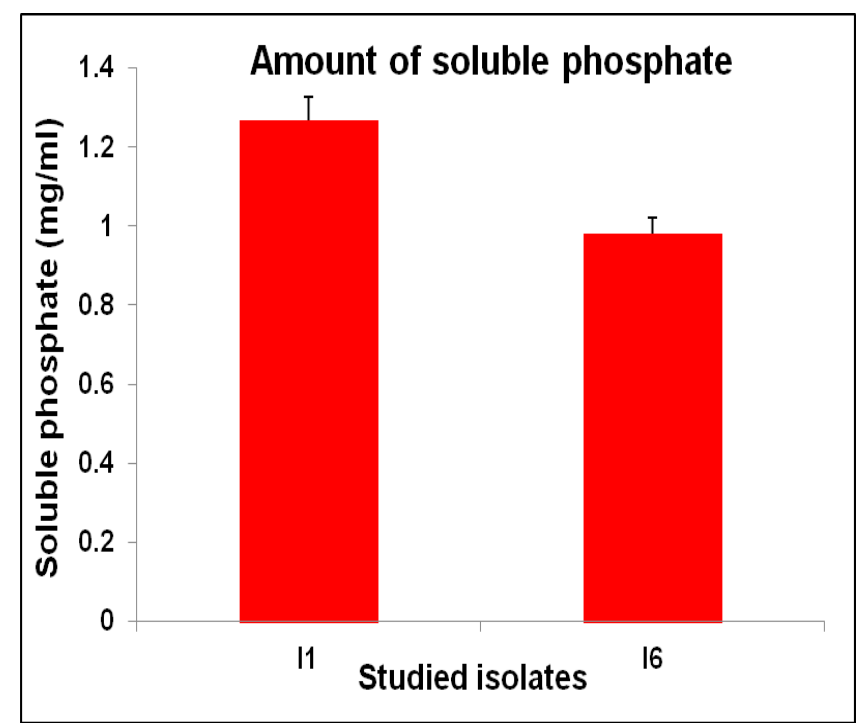

Fig. 2. Amount of soluble phosphae produced by I 1 and I 6 showing the potential ability of phosphate sulubilization of the two isolates.

mg. Between these two isolates I 1 was produced more amount of IAA than I6.

\section{ACC deaminase activity}

Of the two isolates, only the first one showed ACC deaminase activity which was quantified as 0.219 $\mu \mathrm{mol} / \mathrm{mg} / \mathrm{h}$. Growth of I 1 isolate in carbon and Nitrogen-free DF medium supplemented with ACC is indication of ACC deaminase production.

The overall PGPR properties detected for all the studied isolates are presented in Table 1. From the above table it can be seen that among the screened isolates I 1 showed positive activity for all the four chosen characters whereas I 6 showed positive activity for all the selected characters except ACC deaminase activity. Rest of the isolated organisms did not show any positive activity for the screened characters. Based on the PGPR characteristics of the screened isolates I 1 and I 6 were selected for further screening. 


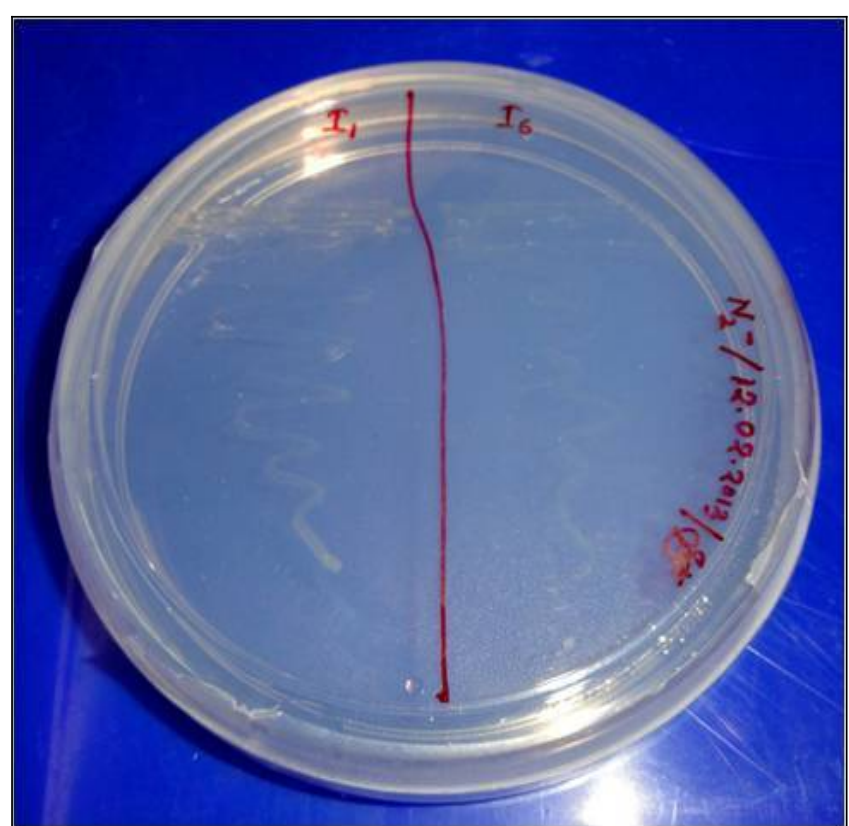

Fig. 3. Growth on Burk's Nitrogen-free medium showing the ability of nitrogen fixatation of isolate 1 and 6 .

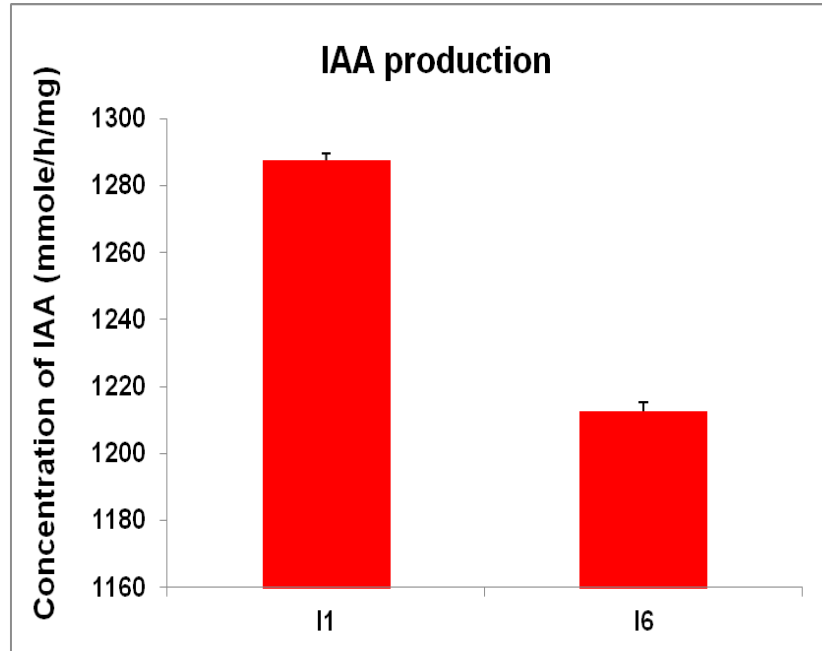

Fig. 4. Amount of indole acetic acid (IAA) in mmole/h/mg showing the capability of IAA production of isolate 1 (I1) and isolate 6 (I6).

\section{Identification}

The derived 16S rDNA sequence from both the isolates showed more than 1000 similar sequences of minimum 98\% similarity with highest significance (zero $E$ value) in homology searching. Both the sequences deposited in NCBI data bank with accession numbers KF059963 and KF705063 respectively. I 1 showed similarity with the sequences of different non-pathogenic Mycobacterium sp. whereas I 6 showed similarity with the sequences of different Bacillus sp. From the phylogenetic analysis, it has been found that I 1 made a separate cluster with Mycobacterium moriokaense (Fig. 5) and I6 showed similarity with Bacillus subtilis (Fig. 6).

\section{Effect of the selected isolates on rice}

Effect of the selected isolates (I 1 and I 6) on rice plant growth and development as germination \%, shoot length (mm), root length (mm), fresh weight of shoot (in gm), fresh weight root (in gm), dry weight shoot (in gm) and dry weight root (in gm) is presented in Fig. $7(A-G)$ and Fig. $8(A-G)$ respectively.

From the figure 7 and 8 it is clear that bothe the isolates increased all the screened parameters of the studied rice germplasm, especially in induced drought. All the studied stress conditions showed positive influence respectively for I 1 and I 6 . In highest stress condition without inoculant the grmplasm unable to grow but with inoculant it showed germination and growth. In case of I 1 it was observed that I 1 had more positive influence in stress conditions than control condition. I 6 showed positive influence in control as well as in induced conditions also but the relativity of influence is more in case of induced stress.

\section{Discussion}

The target area of the study was some drought-prone remote areas of South Bengal because these areas were not well studied before, so the chance of getting novel PGPR may be high. IR64, a drought-sensitive, high-yielding variety was used as it have no positive influence on drought stress. So only the influence of PGPR is reflected in the results.

The PGPR property of the selected isolates was studied for four important properties (phosphate solubilization, IAA production, nitrogen fixation and ACC deaminase production. These four characters are very commonly used for characterization of any microorganisms for their PGPR property (23-26). All the four characters are associated with plant growth and development, which is supposed to confer rice plants to cope with induced drought as experimented. Among the 16 isolates, two showed positive PGPR activity, which on phylogenetic analysis identified as species of Mycobacterium and Bacillus. The Mycobacterium species identified was a non-pathogenic rhizobacteria reported for the first time from the selected area of South Bengal in relation to PGPR activity. The second one was a species of Bacillus which also may be first report from rice field soil in connection with PGPR properties in the same area. The homology searching result showed thousands of sequence similarity with highest significance for both the organisms respectively. So the identification of the organisms are very much evident.

From the screening results, it has been found that both the isolates have positive effect on plant growth and development under control as well as different induced stress conditions. It was also found that the isolates were more effective in the given stress conditions than the control condition. So it can be said that drought stress increase the functionality of the organisms on plant system.

Increase in germination percentage indicates that the organisams can be helpful to increase number of survived seedlings. It may decrease the use of number of seeds that can be economical. As root length increase can be helpful to cope with drought stress (27), it is also evident that the I 1 and I 
Table 1. All the studied characteristics of the screened isolates for PGPR activity.

\begin{tabular}{|c|c|c|c|c|}
\hline Isolates & Phosphate solubilization & Nitrogen fixation & IAA production & ACC deaminase production \\
\hline I 1 & + & + & + & + \\
\hline I 2 & - & - & - & - \\
\hline I 3 & - & - & - & - \\
\hline I 4 & - & - & - & - \\
\hline I 5 & - & - & - & - \\
\hline I 6 & + & + & + & - \\
\hline I 7 & - & - & - & - \\
\hline I 8 & - & - & - & - \\
\hline I 9 & - & - & - & - \\
\hline I 10 & - & - & - & - \\
\hline I 11 & - & - & - & - \\
\hline I 12 & - & - & - & - \\
\hline I 13 & - & - & - & - \\
\hline I 14 & - & - & - & - \\
\hline I 15 & - & - & - & - \\
\hline I 16 & - & - & - & - \\
\hline
\end{tabular}

‘+’ stands for able to produce and ‘-’ stands for unable to produce.

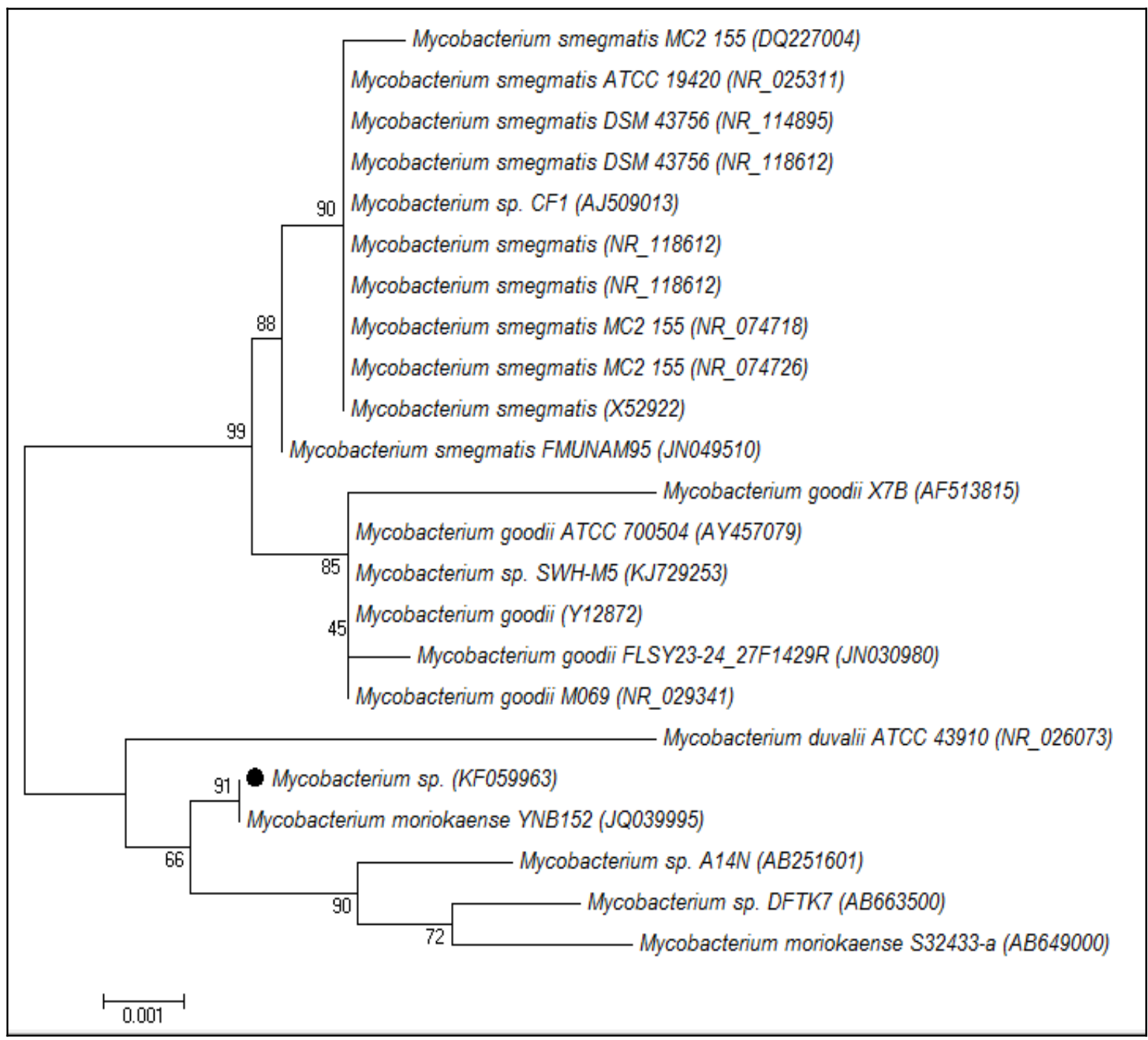

Fig. 5. Phylogenetic position of isolate 1 showing highest and distinctive similarity with Mycobacterium motiokaense.

6 is helping plants to cope with drought. The positive results from other screened traits are also indicating that both the organisms helping rice plants to cope with drought. Moreover, the present study also recommended that I1 is more effective than I6 under different drought stress conditions.

\section{Conclusion}

The available reports on rice field PGPR in relation to drought stress are very less. The present study was thus undertaken to isolate PGPR from rice rhizospheric soil from a typical drought prone 


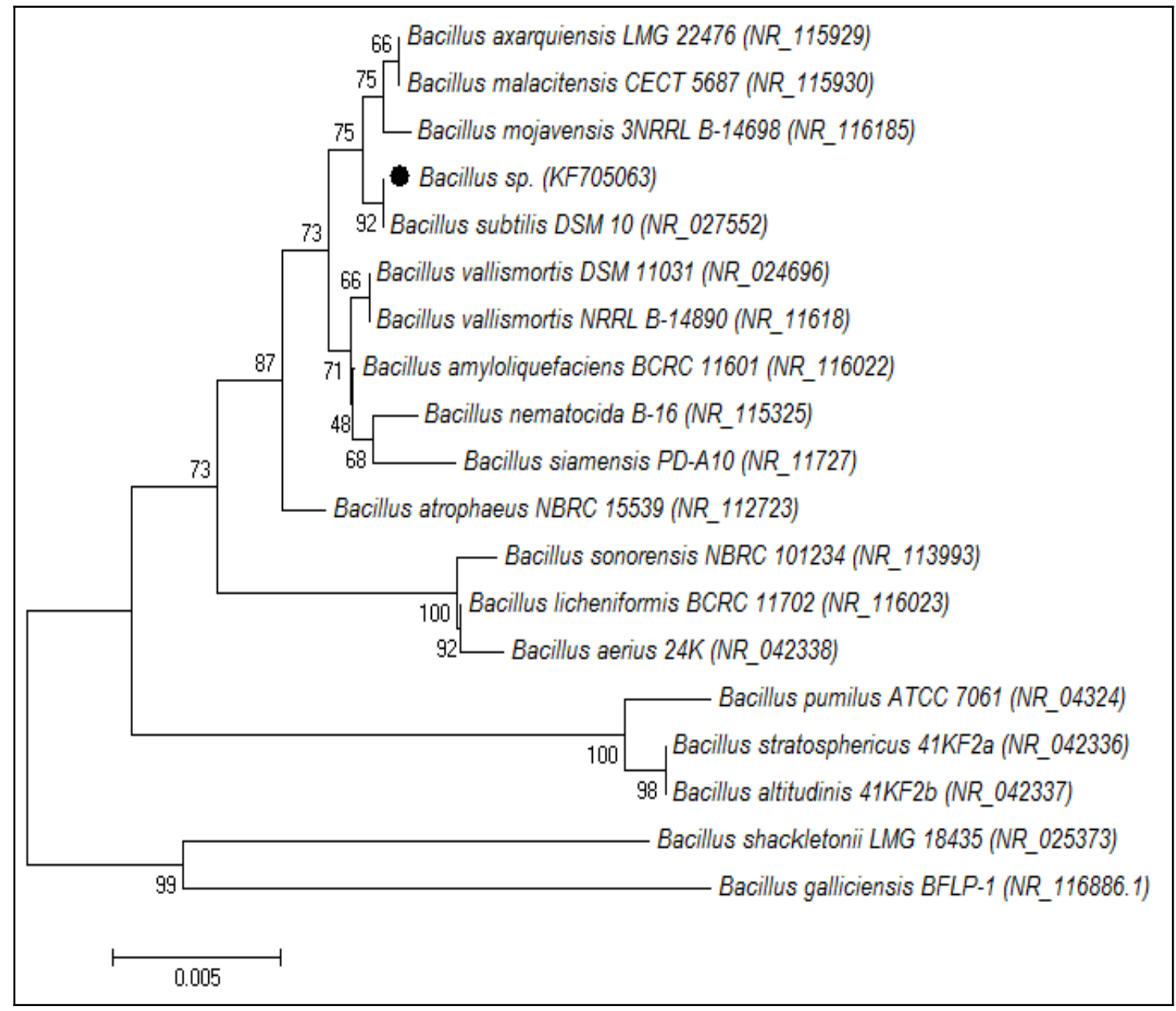

Fig. 6. Phylogenetic position of isolate 6 showing highest similarity with Bacillus subtilis.

upland fields where drought occur year after year. In order to ignore rice plant's own innate drought tolerance potentiality, a high yielding drought susceptible line (var. IR64) was chosen which is at present the most popular lines in upland irrigated rice fields.

From this study it can be concluded that these two isolates (I1 and I6) have potentiality to help rice plants to survive under drought stress conditions. So, field trials with these two organisms can be done for further utilization.

\section{Acknowledgements}

Financial assistance was provided by the Department of Science and Technology, Government of West Bengal [REF. No.: 462 (Sanc.)/ST/P/S\&T/1G-11/2010]. Authors are sincerely grateful to the National Rice Research Institute (NRRI), Cuttack for providing seed materials for this study.

\section{Authors' contributions}

JK carried out the total work and drafted the manuscript. SG carried out the isolation and screening with JK. KP carried out phylogenetic analysis and helped in drafting the manuscript. ND, TKM and RKK participated in the design and coordination of the study. All authors read and approved the final manuscript.

\section{Conflict of interests}

Authors do not have any conflict of interests to declare.

\section{References}

1. Vinocur B, Altman A. Recent advances in engineering plant tolerance to abiotic stress: achievements and limitations. Current Opinion Biotechnol. 2005;16(2):12-132. https://doi.org/ 10:1016/j.copbio.2005.02.001

2. Satterthwaite D, McGranahan G, Tacoli C. Urbanization and its implications for food and farming. Philos Trans R Soc Lond B Biol.Sci.2010;365(1554):2809-20. https://doi.org/10.1098/rstb.2010.0136

3. Laxa M, Liebthal M, Telman W, Chibani K, Dietz KJ. The role of the plant antioxidant system in drought tolerance. Antioxidants. 2019;8(4):94. https://doi.org/10.3390/antiox8040094

4. Oladosu Y, Rafii MY, Samuel C, Fatai A, Magaji U, Kareem I, Kamarudin ZS, Muhammad I, Kolapo K. Drought resistance in rice from conventional to molecular breeding: A Review. Int Mol Sci. 2019;20(14):3519. https://doi.org/10.3390/ijms20143519

5. Sahebi M, Hanafi MM, Rafi MY, Mahmud TMM, Azizi P, Osman M, Abiri R, Taheri S, Kalhori N, Shabanimofrad M, Miah G, Atabaki N. Improvement of drought tolerance in rice (Oryza sativa L.): genetics, genomic tools, and the WRKY gene family. Biomed Res Int. 2018;2018:3158474. https://doi.org/10.1155/2018/3158474 

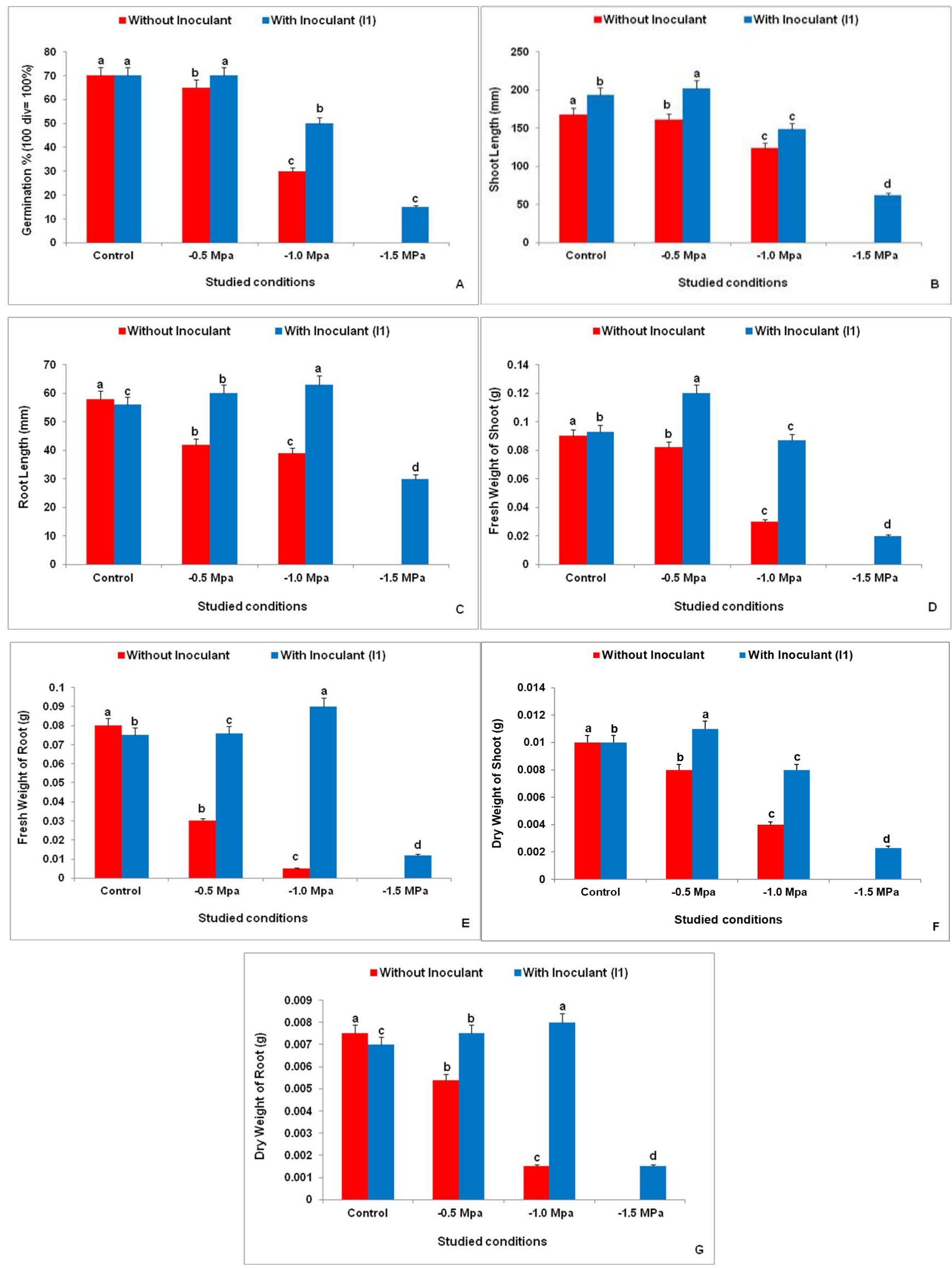

Fig. 7. Effect of isolate $1(A-G)$ on studied rice variety showing significant influence on plant growth and development under induced drought. Bars showing different letters indicate significant differences according to Duncan's test at $p \leq 0.05$. 

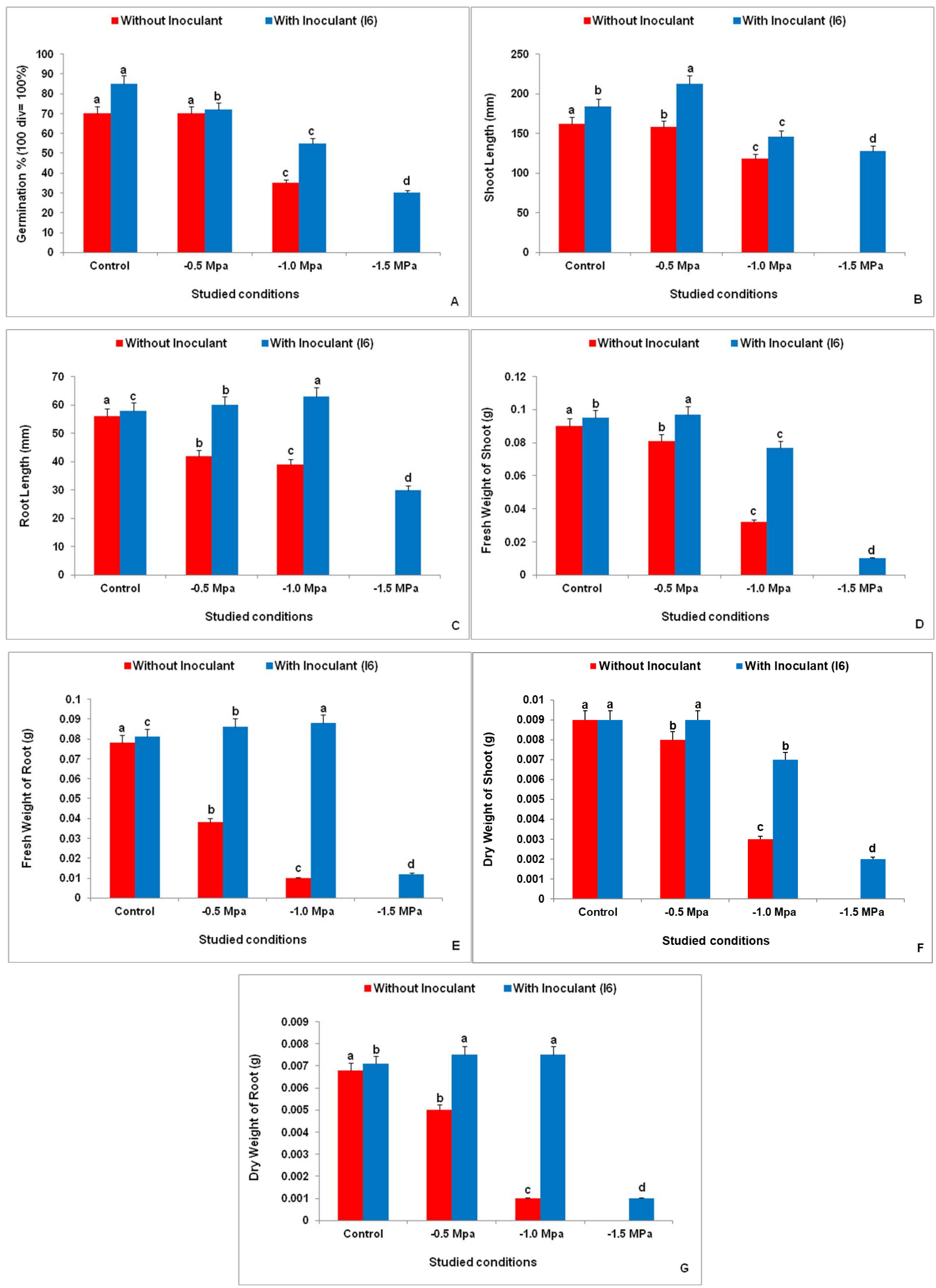

Fig. 8. Effect of isolate 6 (A-G) on studied rice variety showing significant influence on plant growth and development under induced drought. Bars showing different letters indicate significant differences according to Duncan's test at $\mathrm{p} \leq 0.05$. 
6. Dixit S, Singh A, Kumar A. Rice breeding for high grain yield under drought: a strategic solution to a complex problem. Int Agron. 2014, Article 2 ID 863683. https://doi.org/10.1155/2014/863683

7. Vurukonda SSKP, Vardharajula S, Shrivastava M, Ali SkZ. Enhancement of drought stress tolerance in crops by plant growth promoting rhizobacteria. Microbiol Res. 2016;184:1324.

8. Hanks JH, Weintraub RL. The pure culture isolation of ammoniaoxidizing bacteria. Department of Bacteriology, School of Medicine and Department of Botany, The George Washington University, Washington, D. C. 1936.

9. Pikovskaya RI. Mobilization of phosphorus in soil in connection with vital activity of some microbial species. Microbiologiya. 1948;17:362-70.

10. Premono EM, Moawad AM, Vlek PLG. Effect of phosphatesolubilizing Pseudomonas putida on the growth of maize and its survival in the rhizosphere. Indones J Crop Sci. 1996;11:1323.

11. Subba-Rao NS. Soil microorganisms and plant growth, $4^{\text {th }}$ ed. In: Science Publishers Inc., USA; 1999.

12. Davis BD, Mingioli ES. Mutants of Escherichia coli requiring methionine or vitamin $B_{12}$. J Bacteriol. 1950;60:17-28.

13. Gordon SA, Weber RP. Colorimetric estimation of indoleaceticacid. Plant Physiol. 1951;26:192-97.

14. Glick BR, Karaturovic D, Newell P. A novel procedure for rapid isolation of plant growth promoting rhizobacteria. Can J Microbiol. 1995;41:533-36.

15. Dworkin M, Foster JW. Experiments with some microorganisms which utilize ethane and hydrogen. J Bacteriol. 1958;75:592-601.

16. Honma M, Shimomura T. Metabolism of 1-aminocyclopropane1 carboxylic acid. Agric Biol Chem. 1978;42:1825-31.

17. Bradford MM. A rapid and sensitive method for the quantification of microgram quantities of protein utilizing the principle of protein-dye binding. Anal Biochem. 1976;72:24854.

18. Galkiewicz JP, Kellogg CA. Cross-kingdom amplification using bacteria-specific primers: complications for studies of coral microbial echology. Appl Environ Microbiol. 2008;74:7828-31. https://doi.org/10.1128/AEM.01303-08

19. Jukes TH, Cantor CR. Evolution of protein molecules. In: Munro HN, editor. Mammalian protein metabolism. New York: Academic Press, 1969. p. 21-132.

20. Tamura K, Stecher G, Peterson D, Filipski A, Kumar S. MEGA6: Molecular Evolutionary Genetics Analysis Version 6.0. Mol Biol Evol. 2013;30:2725-29.

21. Money NP. Osmotic pressure of aqueous polyethylene glycols: Relationship between molecular weight and vapor pressure deficit. Plant Physiol. 1989;91:766-69.

22. Duncan DB. Multiple range and multiple F tests. Biometrics. 1995;11:1-42.

23. Glick BR, Penrose DM and Li J. A model for lowering plant ethylene concentration by plant growth promoting rhizobacteria. J Theo Biol. 1998;190:63-68.

24. Vessey JK Plant growth promoting rhizobacteria as biofertilizers. Plant Soil. 2003;255:571-86.

25. Zahir AZ, Arshad M and Frankenberger WT Jr. Plant growth promoting rhizobacteria: application and perspectives in agriculture. Adv Agron. 2004;81:97-168.

26. Chen YP, Rekha PD, Arun AB, Shen FT, Lai WA and Young CC Phosphate solubilizing bacteria from subtropical soil and their tricalcium phosphate solubilizing abilities. Appl Soil Ecol. 2006;34:33-41.

27. Kim Y, Chung YS, Lee E, Tripathi P, Heo S, Kim KH. Root response to drought stress in rice (Oryza sativa L.). Int J Mol Sci. 2020;21:1-22. 